\title{
Sustainability of Belgorod Region Enterprises of Building Materials and Building Structures Industry under Sanctions
}

\author{
Irina Aleksandrovna Slabinskaya \\ Accounting and Audit Department \\ Belgorod State Technological University named after \\ V.G. Shoukhov \\ Belgorod, Russia \\ iaslabinskaya@mail.ru
}

\author{
Olga Borisovna Benderskaya \\ Accounting and Audit Department \\ Belgorod State Technological University named after \\ V.G. Shoukhov \\ Belgorod, Russia \\ obenderskaya@gmail.com
}

\begin{abstract}
The paper features the analysis of sustainability of Belgorod Region enterprises dealing with production of construction materials and building structures exemplified by five largest and well-known enterprises of this industry: JSC Melstrom, JSC Stroymaterialy, OJSC Plant ZhBK-1, OJSC Belgorodasbestotsement and OJSC Belgorodstroydetal. Sustainability of an enterprise is understood as its functional performance within an indeterminate amount of time and ability to achieve its objectives under the influence of negative factors. An integrated comparative assessment of enterprises' sustainability in 2016 alongside with their ranking was carried out according to twelve performance indicators (financial stability index, stable working capital-to-production ratio, current liquidity ratio, growth rate ratio in respect of revenue, sales profit, net profit and equity capital, as well as return on sales, total and equity assets). The same indicators were used to analyze sustainability dynamics and to make dynamic complex sustainability assessments for every enterprise during 2013-2016. The paper lists conclusions on negative impact of sanctions with regard to the majority of enterprises under study and on their ability to maintain this sustainability and adequate financial status.
\end{abstract}

Keywords - enterprise management; enterprise sustainability; integrated assessment; enterprise sustainability ranking; Belgorod Region; industry of building materials and structures.

\section{INTRODUCTION}

At present, the society is urgently seeking solutions to the problem of assessing and overcoming the influence of policydriven western sanctions on economic development of the Russian Federation in general and on its individual regions. Due to the critical role that the industry of building materials and building structures plays in the economy of Belgorod Region [1], it is deemed necessary to estimate economic outcomes of Belgorod enterprises of these branches throughout 2016, to analyze their sustainability in 2016 and dynamics in 2013-2016. This paper represents logical followup of [2]. Five mostly known enterprises of the industry of building materials and building structures of Belgorod Region were randomly selected for further monitoring: JSC Melstrom, JSC Stroymaterialy, OJSC Plant ZhBK-1, OJSC
Belgorodasbestotsement and OJSC Belgorodstroydetal (form of entity is specified as of 2016). The study is based on annual financial statements of the aforesaid enterprises.

OJSC Plant ZhBK-1 is the largest of the studied enterprises in terms of property potential. Its book value as of the end of 2016 made 3,013,203 thousand rubles. The property stock of other enterprises amounted to less than 1 billion rubles. OJSC Plant ZhBK-1 is also the leader in sales volumes - in 2016 its revenue made 1,467,143 thousand rubles. The second position in terms of the revenue total in 2016 is taken by OJSC Belgorodasbestotsement with its revenue amounting to $1,114,313$ thousand rubles. In 2016 , three out of five enterprises gained profit on ordinary activities. JSC Stroymaterialy and OJSC Plant ZhBK-1 concluded a year at a loss from sales. However, the final fiscal effect of all enterprises was positive, so it is possible to say that all studied enterprises were profitable in 2016 [3]. Four out of five enterprises had stable working capital (SWC) with the only exception made by JSC Stroymaterialy that has not had any SWC since 2014 [2].

\section{COMPARATIVE INTEGRATED ASSESSMENT AND RANKING OF ENTERPRISES SUSTAINABILITY THROUGHOUT 2016}

Similar to [2] four financial performance indicators, four growth rate indicators defining tendencies of revenue differentials, financial results and equity capital of enterprises over time, as well as four profitability ratios were used as sustainability performance indicators of enterprises. The following indicator values characterize sustainability of enterprises:

- financial stability index - above 0.5 ;

- SWC-to-production ratio - at least 0.6;

- current liquidity ratio - at least 2;

- growth rates - at least $100 \%$;

- profitability ratio - above 0 
The aforesaid values shall be designated as sustainability standards. It should be noted that a specific standard cannot be defined for total assets turnover ratio [4].

Calculation of the specified indicators over 2016 is shown at the top of Table 1, where the best values on each indicator are marked.

In 2016, four enterprises had high values of financial stability which characterizes the ratio of sustainable sources of funding (equity capital and long-term debt capital) in the total capital. Among all enterprises, only JSC Stroymaterialy had insufficient sources of funding.

SWC-to-production ratio of four enterprises was much higher the standard value, which indicates the fact that these enterprises never or almost do not use cheap short-term debt capital to replenish their stocks, however this guarantees against production shut-down due to lack of funding for more than 1 year. OJSC Belgorodstroydetal had the highest SWCto-production ratio (at 282\%). JSC Stroymaterialy had a negative SWC-to-production ratio, i.e. its working capital was entirely financed from short-term debt capital, which could lead to production shut-down [5].

All enterprises, except JSC Stroymaterialy, were solvent in 2016 in terms of their short-term liabilities and their current liquidity ratio exceeded 2. OJSC Plant ZhBK-1 had the highest solvency margin and its current assets were 8.82 times higher the current liabilities. Current liabilities of JSC Stroymaterialy were covered by current assets only by $36 \%$, which indicates the fact that the enterprise failed to discharge them without the sale of fixed assets.

Thus, according to the specified standards, the majority of enterprises, except for JSC Stroymaterialy, had satisfactory financial performance in 2016.

JSC Melstrom had the highest business activity in 2016 with the turnover rate of its total assets amounting to 0.88 percent per year. The business activity of other four enterprises was much lower.

Only two out of five enterprises were marked for their revenue growth in 2016 as compared to 2015, while the same indicator decreased for other enterprises. OJSC Plant ZhBK-1 experienced the maximum decrease in its revenues.

In 2016, only one enterprise - JSC Melstrom - managed to considerably increase its profit on ordinary activities (i.e. sales profit) by $44.1 \%$ in comparison with 2015. Two other enterprises had significant decrease in their sales profit, while in case of JSC Stroymaterialy and OJSC Plant ZhBK-1 it was replaced by loss and, hence, was not calculated. Only JSC Melstrom was able to increase its net profit (with an impressive growth of 292.4\%!) in 2016. The net profit of other three enterprises decreased considerably and OJSC Belgorodstroydetal even experienced a dramatic decrease. This is particularly frustrating since this enterprise demonstrated the highest revenue growth.

In 2016, the equity capital of three out of five enterprises exceeded $100 \%$. In fact, only JSC Melstrom increased its equity capital and was marked by a substantial growth at $7.42 \%$ (however, it should be noted that this only refers to the nominal growth irrespective of inflation) [6]. Only JSC Stroymaterialy and OJSC Plant ZhBK-1 managed to save their equity capital. The equity capital of other two enterprises was reduced with OJSC Belgorodasbestotsement experiencing a substantial decrease by $5.06 \%$.

JSC Melstrom was the leader in all profitability indices in 2016. It is noteworthy that the level of all profitability indices was relatively modest for all enterprises under study.

An integrated assessment (IA) calculated via the modified score was used to compare sustainability of enterprises [7]:

TABLE I. INDICATORS, COMPARATIVE INTEGRATED ASSESSMENT AND RANKING OF ENTERPRISES SUSTAINABILITY THROUGHOUT 2016

\begin{tabular}{|c|c|c|c|c|c|}
\hline \multirow{2}{*}{$\begin{array}{l}\text { Indicator, } \\
\text { units }\end{array}$} & \multicolumn{5}{|c|}{ Individual Performance Indicators } \\
\hline & JSC Melstrom & $\begin{array}{c}\text { JSC } \\
\text { Stroymaterialy }\end{array}$ & $\begin{array}{c}\text { OJSC Plant } \\
\text { ZhBK-1 }\end{array}$ & $\begin{array}{c}\text { OJSC } \\
\text { Belgorodasbesto- } \\
\text { tsement }\end{array}$ & $\begin{array}{c}\text { OJSC Belgorodstroy- } \\
\text { detal }\end{array}$ \\
\hline 1) financial stability index (annual average) & 0.76 & 0.22 & 0.94 & 0.84 & 0.86 \\
\hline 2) SWC-to-production ratio (annual average) & 1.09 & -3.12 & 2.40 & 0.98 & 2.82 \\
\hline 3) current liquidity ratio (annual average) & 2.46 & 0.36 & 8.82 & 5.43 & 5.01 \\
\hline 4) total assets turnover ratio & 0.88 & 0.28 & 0.12 & 0.38 & 0.26 \\
\hline 5) revenue growth rate, $\%$ & 111.46 & 92.38 & 88.42 & 91.97 & 119.92 \\
\hline 6) sales profit growth rate, $\%$ & 144.10 & - & - & 50.80 & 36.26 \\
\hline 7) net profit growth rate, $\%$ & 392.40 & 85.53 & 17.30 & 49.62 & 2.86 \\
\hline 8) equity assets growth rate, $\%$ & 107.42 & 100.46 & 100.75 & 94.94 & 98.52 \\
\hline 9) return on sales profit, $\%$ & 6.96 & 5.51 & -0.05 & 4.84 & 1.40 \\
\hline
\end{tabular}




\begin{tabular}{|c|c|c|c|c|c|}
\hline 10) return on net profit, $\%$ & 2.06 & 0.08 & 1.40 & 1.81 & 0.06 \\
\hline 11) return on total assets, $\%$ & 5.94 & 0.16 & 0.48 & 2.18 & 0.04 \\
\hline 12) return on equity, $\%$ & 4.80 & 0.23 & 0.37 & 1.70 & 0.03 \\
\hline \multicolumn{6}{|l|}{ Indicator scores: } \\
\hline 1) & 7.56 & 0 & 10 & 8.59 & 8.98 \\
\hline 2) & 7.08 & 0 & 9.29 & 6.90 & 10 \\
\hline 3) & 2.48 & 0 & 10 & 5.99 & 5.50 \\
\hline 4) & 10 & 2.03 & 0 & 3.37 & 1.82 \\
\hline 5) & 7.31 & 1.26 & 0 & 1.13 & 10 \\
\hline 6) & 10 & 0 & 0 & 3.53 & 2.52 \\
\hline 7) & 10 & 2.12 & 0.37 & 1.20 & 0 \\
\hline 8) & 10 & 4.42 & 4.65 & 0 & 2.87 \\
\hline 9) & 10 & 0 & 4.38 & 8.30 & 5.54 \\
\hline 10) & 10 & 0.11 & 6.70 & 8.74 & 0 \\
\hline 11) & 10 & 0.19 & 0.75 & 3.63 & 0 \\
\hline 12) & 10 & 0.40 & 0.71 & 3.49 & 0 \\
\hline Integrated assessment (IA) & 8.70 & 0.88 & 3.90 & 4.57 & 3.93 \\
\hline Ranking position & 1 & 5 & 4 & 2 & 3 \\
\hline
\end{tabular}

$$
\mathrm{IA}_{i}=\frac{\sum_{j=1}^{m} b_{i j}}{m}, \quad i=\overline{1, n} \text {; }
$$

$$
b_{i j}=b_{\min }+\frac{a_{i j}-a_{\text {worst }}}{a_{\text {bestj }}-a_{\text {worst }}}\left(b_{\max }-b_{\text {min }}\right) \text {. }
$$

Here, IA - an integrated assessment; $\mathrm{n}$ - the number of enterprises being compared (in our case $n=5$ ); $m$ - number of indicators (in our case $m=12$ ); $a_{i j}$ - the value of $j$-indicator of $i$-enterprise; $b_{i j}-$ score of $j$-indicator of $i$-enterprise; $a_{\text {worst } j}$ and $a_{\text {best } j}$ - respectively, the worst and the best among $j$-indicator values; $b_{\min }$ and $b_{\max }$ - respectively, the minimum and maximum score values which correspond to the worst and best indicator values; $b_{\min }=0 ; b_{\max }=10$. The value of IA (1) may vary from 0 to 10 . If $\mathrm{IA}=0$, the enterprise under assessment is worse than other enterprises with regard to all assessment indicators and if IA $=10$, the enterprise is better than the others in all indicators. It should be noted that IA values thus calculated characterize relative (but not absolute) level of enterprise sustainability, i.e. their level against the level of other enterprises. Consequently, if IA $=10$, it does not mean that the enterprise is sustainable (and if IA $=0$, it does not mean that sustainability is absent) [8].

Calculation of indicator scores and the IA of enterprises are given at the bottom of Table 1. Ranking of enterprises sustainability based on IA values is presented in the baseline of Table 1 .
Let us comment on the obtained results. JSC Melstrom became an absolute leader in sustainability in 2016. The values of all sustainability indicators of this enterprise are within the normal range. Its IA equals 8.7 being sufficiently close to the maximum possible score of 10 . The reasons for this can be easily traced according to scores of enterprise indicators. The average score of JSC Melstrom according to eight out of twelve indicators equals 10: it demonstrated the highest business activity, impressive net profit growth, the highest (in comparison with other participants of the assessment) level of profitability and ability to increase its equity capital [9]. It can be concluded that sustainability of JSC Melstrom is high.

OJSC Belgorodasbestotsement was not leading in any indicator. Nevertheless, the enterprise was ranked the second due to sufficient values of financial stability and return on sales. However, the level of its integrated assessment is below average (4.57). Four indicators of the enterprise show unsatisfactory values, and one of them - equity assets growth rate - has the worst value in comparison with other enterprises, hence, sustainability of OJSC Belgorodasbestotsement is not absolute (it can simply be called normal) [10].

OJSC Belgorodstroydetal, which takes the third position, is the leader in SWC-to-production ratio and revenue growth rate, but fails to meet sustainability requirements in sales profit and equity assets growth rates. Besides, compared to other enterprises, it has the worst values in four indicators [11]. 
In comparison with other enterprises, OJSC Plant ZhBK-1, which turned to be the fourth, has the best values of financial stability and current liquidity, but fails to meet sustainability requirements in revenue and profit growth rates, as well as in return on sales profit. The values of its three indicators are worse than the same values of other enterprises [12].

It can be concluded that sustainability of OJSC Belgorodstroydetal and OJSC Plant ZhBK-1is satisfactory.

JSC Stroymaterialy takes the last place in the ranking. Its IA is close to zero; the values of half of its indicators are unsatisfactory; the values of its five indicators are worse than the same values of other enterprises. It can be concluded that JSC Stroymaterialy has poor sustainability performance.

According to IA values, it is easy to estimate to what extent the sustainability of some enterprises is lower than that of others. Hence, the integrated assessment of JSC Melstrom sustainability is 1.9 times higher than that of OJSC Belgorodasbestotsement, which follows the former in ranking, i.e. the sustainability of JSC Melstrom is almost twice higher than that of OJSC Belgorodasbestotsement. OJSC Belgorodstroydetal and OJSC Plant ZhBK-1 are relatively close in their sustainability, and JSC Stroymaterialy is seen as an absolute outsider [13].

\section{ANALYSIS OF SUSTAINABILITY DYNAMICS IN 2013-2016}

In order to understand the changes in sustainability of enterprises over time, the authors calculated their sustainability indicators for 2013-2016, and based on them they were able to calculate dynamic IA of each enterprise (for calculation of dynamic IA we compared values of indicators of one and the same enterprise throughout different years). Dynamic integrated assessment was made via the modified method scores (1-2) where $n$ - the number of years being compared (in our case $n=4$ ); $m$ - number of indicators (12); $a_{i j}$ - value of $j$-indicator of an enterprise within $i$-year; $b_{i j}-$ score of $j$-indicator of an enterprise within $i$-year; $a_{\text {worst } j}$ and $a_{\text {best } j}$ - respectively, the worst and the best among values of $j$ indicator for 2013-2016; $b_{\min }=0 ; b_{\max }=10$. IA $=0$, if values of all indicators of an enterprise during this period are worse than those in other periods; IA $=10$, if values of all indicators of an enterprise during this period are better than those in other periods.

Values of sustainability indicators of enterprises in 20132016 and results of dynamic IA calculation are given in Tables $2-4$.

JSC Melstrom was rather stable in 2013: only current liquidity ratio fell below the standard, and the IA value was above average (6.55). The enterprise was poorly functioning in 2014 when three growth rate indicators ceased to correspond to the standard (revenue, sales profit and net profit of the enterprise decreased) and, respectively, profitability indicators, and the current liquidity ratio although increased but failed to reach the standard. The above mentioned makes it possible to conclude that the dynamic IA of JSC Melstrom sustainability in 2014 was critically low. In 2015-2016, all indicators of the enterprise improved and conformed to standard requirements, so it is fair to say that the enterprise was functioning steadily, sustainability was high thus gradually increasing and reaching its maximum in 2016.

TABLE II. INDICATORS AND DYNAMIC INTEGRATED ASSESSMENT OF JSC MELSTROM AND JSC STROYMATERIALY IN $2013-2016$

\begin{tabular}{|l|c|c|c|c|c|c|c|c|}
\hline \multirow{2}{*}{ Indicator } & \multicolumn{9}{|c|}{ Individual Performance Indicators } \\
\cline { 2 - 11 } & \multicolumn{3}{|c|}{ JSC Melstrom } & \multicolumn{5}{c|}{ JSC Stroymaterialy } \\
\cline { 2 - 11 } & $\mathbf{2 0 1 3}$ & $\mathbf{2 0 1 4}$ & $\mathbf{2 0 1 5}$ & $\mathbf{2 0 1 6}$ & $\mathbf{2 0 1 3}$ & $\mathbf{2 0 1 4}$ & $\mathbf{2 0 1 5}$ & $\mathbf{2 0 1 6}$ \\
\hline 1 ) & 0.60 & 0.66 & 0.72 & 0.76 & 0.36 & 0.30 & 0.27 & 0.22 \\
\hline 2$)$ & 0.82 & 0.93 & 1.05 & 1.09 & -1.75 & -3.10 & -3.62 & -3.12 \\
\hline 3$)$ & 1.61 & 1.80 & 2.09 & 2.46 & 0.45 & 0.38 & 0.37 & 0.36 \\
\hline 4$)$ & 0.86 & 0.76 & 0.79 & 0.88 & 0.41 & 0.47 & 0.33 & 0.28 \\
\hline 5$)$ & 104.07 & 88.19 & 101.79 & 111.46 & 78.65 & 207.71 & 108.54 & 92.38 \\
\hline 6$)$ & 146.18 & 46.96 & 113.11 & 144.10 & - & - & 95.06 & - \\
\hline 7$)$ & 151.85 & 13.83 & 179.44 & 392.40 & - & - & 37.95 & 85.53 \\
\hline 8$)$ & 116.09 & 105.19 & 104.37 & 107.42 & 21.98 & 13726.84 & 100.54 & 100.46 \\
\hline 9$)$ & 9.10 & 4.84 & 5.38 & 6.96 & -8.96 & 1.91 & 1.67 & -5.51 \\
\hline 10$)$ & 2.12 & 0.33 & 0.58 & 2.06 & -0.92 & 0.24 & 0.08 & 0.08 \\
\hline 11$)$ & 6.61 & 1.68 & 2.09 & 5.94 & -0.53 & 0.48 & 0.18 & 0.16 \\
\hline 12$)$ & 6.03 & 0.76 & 1.30 & 4.80 & -63.96 & 1.40 & 0.27 & 0.23 \\
\hline IA & 6.55 & 0.92 & 3.82 & 8.61 & 3.07 & 6.73 & 4.90 & 3.52 \\
\hline
\end{tabular}


2013 was the worst year for JSC Stroymaterialy when its financial performance was negative and all eleven specified indicators were unsatisfactory. It is obvious that the enterprise was unstable in 2013. In 2014, the enterprise managed to get profit and to considerably increase its equity capital, due to which the six indicators joined the range of normal values and the enterprise reached the maximum integrated assessment during 2013-2016. So, it is possible to say that in 2014 JSC Stroymaterialy was relatively close to being sustainable. However, in the following years the situation gradually became worse, especially in 2016 when the enterprise experienced the loss on sales, which led to IA decrease almost to the level of 2013.

Data of OJSC Plant ZhBK-1 and OJSC Belgorodasbestotsement are shown in Table 3. IA values demonstrate that both enterprises experienced the decrease in their sustainability from year to year. The main difference is that sustainability of OJSC Plant ZhBK-1 decreased rather steadily throughout the entire period of study, while in case of OJSC Belgorodasbestotsement a smooth decrease was replaced by a dramatic fall in 2016 .

In 2013, eight indicators of OJSC Plant ZhBK-1 satisfied the standard assessments, hence its sustainability during that period may be considered normal. Throughout the entire period of study the enterprise experienced decrease in revenue, sales and net profits which caused its failure to meet the standard growth rates. In 2016, the situation got worse due to sale losses. Earlier in this paper it was already mentioned that sustainability of OJSC Plant ZhBK-1 in 2016 was assessed as satisfactory. Thus, the level of enterprise sustainability decreased from normal to satisfactory over time.

In 2013, the sustainability of OJSC Belgorodasbestotsement was high since all eleven specified indicators had normal values. In 2014, the sales profit of the enterprise decreased; in 2015, it followed the decrease in its revenue, net profit and equity capital; in 2016, these processes continued. Indicators, which remained within the range of normal values, also worsened over time. As a result, IA of OJSC Belgorodasbestotsement reached the lowest level in 2016. Finally, it can be concluded that sustainability of OJSC Belgorodasbestotsement decreased over time from high to normal, and taking into account sharp deterioration in 2016, there is a risk that in 2017 the enterprise may reach its satisfactory level.

TABLE III. INDICATORS AND DYNAMIC INTEGRATED ASSESSMENT OF OJSC PLANT ZHBK-1 AND OJSC BELGORODASBESTOTSEMENT IN 2013-2016

\begin{tabular}{|l|c|c|c|c|c|c|c|c|}
\hline \multirow{2}{*}{ Indicator } & \multicolumn{9}{|c|}{ Individual Performance Indicators } \\
\cline { 2 - 10 } & \multicolumn{3}{|c|}{ OJSC Plant ZhBK-1 } & \multicolumn{5}{c|}{ OJSC Belgorodasbestotsement } \\
\cline { 2 - 10 } & $\mathbf{2 0 1 3}$ & $\mathbf{2 0 1 4}$ & $\mathbf{2 0 1 5}$ & $\mathbf{2 0 1 6}$ & $\mathbf{2 0 1 3}$ & $\mathbf{2 0 1 4}$ & $\mathbf{2 0 1 5}$ & $\mathbf{2 0 1 6}$ \\
\hline 1$)$ & 0.91 & 0.90 & 0.91 & 0.94 & 0.85 & 0.86 & 0.88 & 0.84 \\
\hline 2$)$ & 1.43 & 1.82 & 2.18 & 2.40 & 0.92 & 0.94 & 1.03 & 0.98 \\
\hline 3$)$ & 4.96 & 5.14 & 6.58 & 8.82 & 4.59 & 5.23 & 6.40 & 5.43 \\
\hline 4$)$ & 0.22 & 0.18 & 0.13 & 0.12 & 0.46 & 0.43 & 0.42 & 0.38 \\
\hline 5$)$ & 96.53 & 93.94 & 77.46 & 88.42 & 101.64 & 100.18 & 96.20 & 91.97 \\
\hline 6$)$ & 88.19 & 64.46 & 57.19 & - & 194.13 & 95.96 & 73.00 & 50.80 \\
\hline 7$)$ & 88.03 & 69.76 & 56.04 & 17.30 & 519.19 & 110.88 & 42.28 & 49.62 \\
\hline 8$)$ & 114.37 & 108.81 & 104.52 & 100.75 & 110.13 & 106.84 & 96.82 & 94.94 \\
\hline 9$)$ & 18.63 & 12.79 & 9.44 & -0.05 & 12.05 & 11.54 & 8.76 & 4.84 \\
\hline 10$)$ & 13.31 & 9.88 & 7.15 & 1.40 & 6.88 & 7.62 & 3.35 & 1.81 \\
\hline 11$)$ & 7.58 & 4.52 & 2.49 & 0.48 & 8.25 & 8.57 & 3.82 & 2.18 \\
\hline 12$)$ & 6.71 & 4.20 & 2.21 & 0.37 & 7.72 & 7.90 & 3.29 & 1.70 \\
\hline IA & 7.69 & 5.47 & 3.81 & 2.98 & 7.50 & 6.51 & 4.61 & 0.87 \\
\hline
\end{tabular}

Assessment of OJSC Belgorodstroydetal sustainability dynamics is presented in Table 4. In 2013, the level of its sustainability can be compared with that of OJSC Plant ZhBK1. Both enterprises faced a decrease in revenue and profit. In addition, JSC Plant ZhBK-1 had better profitability indicators, while OJSC Belgorodstroydetal had high financial stability indicators. So, it is possible to conclude that sustainability of
OJSC Belgorodstroydetal in 2013 was normal. In 2014, the enterprise managed to slow down the decrease in profits, slightly strengthened its financial status and reached the maximum sustainability level during 2013-2016. In 2015, the enterprise faced insignificant deterioration in the majority of indicators and, as a result, the decrease in IA. In 2016, it experienced a profit slump and, hence the profitability level 
which followed (although insignificant) reduction of financial stability. As a result, the sustainability level of OJSC Belgorodstroydetal decreased from normal in 2013 to satisfactory in 2016. Such downward trend in 2016 poses a risk of the enterprise losing its ability to function steadily in 2017.

\section{CONCLUSIONS}

The results of the analysis covering five enterprises of the industry of building materials and building structures of Belgorod Region are not encouraging and make it possible to conclude that the economic crisis in Russia, caused by western sanctions, adversely affected the sustainability of the most [14].

\section{TABLE IV.}

INDICATORS AND DYNAMIC INTEGRATED ASSESSMENT OF OJSC BELGORODSTROYDETAL IN 2013-2016

\begin{tabular}{|c|c|c|c|c|}
\hline \multirow[t]{2}{*}{ Indicator } & \multicolumn{4}{|c|}{$\begin{array}{c}\text { Individual Performance Indicators } \\
\text { OJSC Belgorodstroydetal }\end{array}$} \\
\hline & 2013 & 2014 & 2015 & 2016 \\
\hline 1) & 0.93 & 0.93 & 0.91 & 0.86 \\
\hline 2) & 2.38 & 2.74 & 2.83 & 2.82 \\
\hline 3) & 8.88 & 8.77 & 6.64 & 5.01 \\
\hline 4) & 0.23 & 0.21 & 0.23 & 0.26 \\
\hline 5) & 92.03 & 92.01 & 116.60 & 119.92 \\
\hline 6) & 54.51 & 68.23 & 80.82 & 36.26 \\
\hline 7) & 51.43 & 90.35 & 83.98 & 2.86 \\
\hline 8) & 101.11 & 102.11 & 101.86 & 98.52 \\
\hline 9) & 8.98 & 6.66 & 4.62 & 1.40 \\
\hline 10) & 3.32 & 3.26 & 2.35 & 0.06 \\
\hline 11) & 2.60 & 1.94 & 1.18 & 0.04 \\
\hline 12) & 1.66 & 1.48 & 1.21 & 0.03 \\
\hline IA & 6.79 & 7.31 & 7.11 & 2.48 \\
\hline
\end{tabular}

Two enterprises experienced strong deterioration throughout the entire period of study and two others - during the last two years. Sustainability of three out of five enterprises in 2016 was lower than that in 2013. Besides, in 2016, downward trends of two enterprises were dominating. Only one enterprise was able to reach higher sustainability in 2016 compared to 2013. Nevertheless, the majority of enterprises maintain their sustainability and normal financial status primarily due to competent management of their assets and capital [15]: they keep a high level of sustainable sources of funding and SWC, and hence, a high level of solvency under current liabilities.

\section{Acknowledgments}

The study is implemented under the Flagship University Development Program of Belgorod State Technological University named after V.G. Shukhov.

\section{References}

[1] Y.A. Doroshenko and A.A. Klimashevskaya, "The analysis of scientific and technical potential of the enterprises of construction materials industry in the context of assessment of need of carrying out technological modernization for the industry," in Bulletin of BSTU named after V.G. Schukhov, vol. 1, January 2017, pp. 214-218.

[2] I.A. Slabinskaya and O.B. Benderskaya, "A comparative assessment of the sustainability of Belgorod building materials industry enterprises in 2014-2015," in Bulletin of BSTU named after V.G. Schukhov, vol. 2, pp. 248-254, February 2017.

[3] L.V. Usatova, E.V. Arskaya and O.A. Budnichenko, "The importance of profit and mechanism of its distribution in modern conditions" in Belgorod economic bulletin, vol. 3 (75), pp. 175-186, 2014.

[4] S.M. Bukhonova, Yu.A. Doroshenko and E.V. Trunov, "Application of sustainability performance indicators in company management" in Economic analysis: theory and practice, vol. 9, pp. 10-21, 2004.

[5] Yu.A. Tkachenko and E.V. Kurilo, "Problems in ensuring economic stability of a business unit" in Belgorod economic bulletin, vol. 3 (83), pp. 62-66, 2016

[6] P.N. Tupikin, "Some aspects in creating an economic stability system of a business unit" in Belgorod economic bulletin, vol. 4 (84), pp. 85-89, 2016.

[7] O.B. Benderskaya and I.A. Slabinskaya, Methods of analytical rese, 2015arch, Belgorod: Publishing House of BSTU named after V.G. Shukhov, pp. 103-104.

[8] M.V. Shevchenko and E.A. Kosyanov, "Big Data: problems, prospects and interrelation with economic system" in Belgorod economic bulletin, vol. 4 (84), pp. 31-35, 2016.

[9] Yu.A. Doroshenko, S.M. Bukhonova, I.V. Somina and K.A. Klimashevsky, "The study of synergistic effect in investment and innovative activity of enterprises within building materials industry" in Industrial and civil engineering, vol. 12, pp. 33-36, December 2014.

[10] Yu.A. Doroshenko and M. Golubotskikh, "Factors of competitive sustainability and assessment of their influence on enterprises within building materials industry" in Belgorod economic bulletin, vol. 1 (85), pp. 26-31, 2017.

[11] L.N. Kravchenko and E.O. Hodorenko, "The issue of efficiency improvement with regard to company's economic activity" in the Belgorod economic bulletin, vol. 1 (85), pp. 202-209, 2017.

[12] E.D. Schetinina, M.S. Starikova, K.S. Borzenkova, E.N. Chizhova and G.A. Androsova, "The development of the business strategy based on the commercialization of innovations," in International Journal of Applied Engineering Research, vol. 9(22), pp. 16881-16890, 2014.

[13] Y.A. Doroshenko, S.M. Bukhonova, I.V. Somina and A.V. Manin, "Modernization of model for initiation of investment projects as a factor of 164 balanced maintenance of region's investment-innovational activity," in Journal of Applied Engineering Science, vol. 12, № 4, pp. 265-272, 2014

[14] E.N. Chizhova and O.O. Vesnina, "Formation of the innovative environment by klasteriation of the construction industry," in Bulletin of BSTU named after V.G. Shoukhov, vol. 3, pp. 151-155, March 2017.

[15] E.N. Chizhova and M.V. Shevchenko, "Integral efficiency of management system of the industrial enterprise," in Bulletin of BSTU named after V.G. Shoukhov, vol. 1, pp. 95-99, January 2011. 